\title{
CHIHUAHUAN DESERT KANGAROO RATS: NONLINEAR EFFECTS OF POPULATION DYNAMICS, COMPETITION, AND RAINFALL
}

\author{
Mauricio Lima, ${ }^{1,6}$ S. K. Morgan Ernest, ${ }^{2}$ James H. Brown, ${ }^{3}$ Andrea Belgrano, ${ }^{4}$ and Nils Chr. Stenseth ${ }^{5}$ \\ ${ }^{1}$ Center for Advanced Studies in Ecology and Biodiversity (CASEB), Pontificia Universidad Católica de Chile, \\ Casilla 114-D, Santiago CP 6513677 Chile \\ ${ }^{2}$ Department of Biology, Utah State University, Logan, Utah 84322 USA \\ ${ }^{3}$ Department of Biology, University of New Mexico, Albuquerque, New Mexico 87131 USA \\ ${ }^{4}$ Swedish Board of Fisheries, Institute of Marine Research, Lysekil SE-45321 Sweden \\ ${ }^{5}$ Centre of Ecological and Evolutionary Synthesis (CEES), Department of Biology, University of Oslo, \\ P.O. Box 1066 Blindern, NO-0316, Oslo, Norway
}

\begin{abstract}
Using long-term data on two kangaroo rats in the Chihuahuan Desert of North America, we fitted logistic models including the exogenous effects of seasonal rainfall patterns. Our aim was to test the effects of intraspecific interactions and seasonal rainfall in explaining and predicting the numerical fluctuations of these two kangaroo rats. We found that logistic models fit both data sets quite well; Dipodomys merriami showed lower maximum per capita growth rates than Dipodomys ordii, and in both cases logistic models were nonlinear. Summer rainfall appears to be the most important exogenous effect for both rodent populations; models including this variable were able to predict independent data better than models including winter rainfall. $D$. merriami was also negatively affected by another kangaroo rat (Dipodomys spectabilis), consistent with previous experimental evidence. We hypothesized that summer rainfall influences the carrying capacity of the environment by affecting seed availability and the intensity of intraspecific competition.
\end{abstract}

Key words: Chihuahuan Desert; desert rodents; Dipodomys merriami; Dipodomys ordii; Dipodomys spectabilis; interspecific competition; kangaroo rat; limiting factors; population processes; summer rainfall; theoretical models.

\section{INTRODUCTION}

One of the pressing contemporary issues in ecology is predicting the responses of populations to climate change (Stenseth et al. 2002, Walther et al. 2002). Decades of research into the relative roles of endogenous factors (i.e., density dependence) and exogenous factors (i.e., climate) have revealed that both are important drivers of population dynamics (Nicholson 1933, Andrewartha and Birch 1954). In addition, because climate potentially can have direct or indirect impacts on populations, one key issue for predicting the effects of global climate change on population dynamics is how to include exogenous variables in population models (Royama 1992, Sæther et al. 2000, Stenseth et al. 2002, Berryman and Lima 2006, Lima and Berryman 2006, Lima et al. 2006).

Since Elton (1924), the numerical fluctuations of small-mammal populations have provided insights into the factors driving population dynamics, proving especially useful in deciphering the role of endogenous and exogenous factors (Leirs et al. 1997, Lewellen and Vessey 1998, Lima et al. 1999, 2001, 2002a, b, 2006, Stenseth 1999, Stenseth et al. 2002). In particular, rodents inhabiting deserts represent an excellent system

Manuscript received 31 July 2007; revised 14 December 2007; accepted 23 January 2008. Corresponding Editor: F. He.

6.E-mail: mlima@bio.puc.cl for studying the effects of climate on population dynamics. Climate can be an important driver in deserts because of the pulses of productivity, often in the form of desert blooms, that frequently occur after heavy rainfall events (Holmgren et al. 2001, Jaksic 2001, Brown and Ernest 2002). In these ecosystems, years with unusually high rainfall can produce a cascade of ecological events characterized by increases in plant cover, seeds, insects, and finally, small-mammal consumers (Jaksic et al. 1997, Lima et al. 1999, 2002b, 2006, Jaksic 2001). Nevertheless, this simple pattern has been challenged in semiarid systems of southwestern North America (Brown and Ernest 2002) because of the apparent complexity and nonlinearity of the relationship between rainfall and rodent dynamics (Brown and Ernest 2002). In fact, the population dynamics of the small mammals in response to rainfall variability at one study site in the Chihuahuan Desert do not appear to follow the common view of rainfall $\rightarrow$ plants $\rightarrow$ rodents (Jaksic et al. 1997) because the rodent dynamics appear to be uncoupled from the rainfall pattern (Ernest et al. 2000, Brown and Ernest 2002). A previous study using other sites in the region (Ernest et al. 2000) suggested that the highly localized and variable nature of summer precipitation may play an important role in the complex population dynamics. In addition to any direct effects of climate, some studies have suggested that biotic interactions may intensify with increasing precipitation, 
dampening the population response to precipitation as competitors, predators, and diseases also increase (Lima et al. 1999, Brown and Ernest 2002). The importance of climate in driving these systems, the high variability in precipitation from season to season and year to year, and the influence of biotic interactions such as competition make the Chihuahuan Desert an ideal system for studying how to incorporate climate into population models.

Based on this understanding, we developed simple conceptual models for the postulated rainfall effects and used independent data for testing model predictions. We focused on the effects of seasonal rainfall and intrinsic feedback mechanisms on population dynamics of two small-rodent species inhabiting the Chihuahuan Desert in southwestern North America. We analyzed the irregular fluctuations exhibited by two kangaroo rats using theory-based population dynamic models (Royama 1992, Berryman 1999). In particular, Royama (1992) provides an organized approach for evaluating the effect of exogenous (climatic) factors on population dynamics. Using this method, we could include logical explanations of the possible effects of climate on demographic rates in the population dynamic models (Royama 1992).

\section{Materials And Methods}

\section{Study site}

The Portal Project was initiated by James H. Brown and associates in the summer of 1977. The site (elevation $1330 \mathrm{~m}$ ) is located near the town of Portal, Arizona, USA, on a bajada (a sandy or gravelly alluvial fan forming a debris slope) at the base of the Chiricahua Mountains (Fig. 1). The 20-ha site is fenced with barbed wire to exclude cattle and within this cattle exclosure there are 24 fenced experimental plots. Each plot is 0.25 ha and contains a $7 \times 7$ grid of permanently marked trapping stations. These plots were randomly assigned to a variety of rodent treatments, with a subset reserved as controls. Only data from the 10 control plots were used for these analyses. For more information on the site and methodology, see Brown (1998).

\section{Climate data}

Rainfall in the Chihuahuan Desert occurs in two distinct rainy seasons: winter and summer. These rainy seasons are generated by different climatic processes that result in different patterns for winter and summer precipitation. Winter precipitation results from broad frontal storms covering potentially hundreds of miles (Mock 1996). In contrast, summer precipitation results from more localized convective thunderstorms (Mock 1996).

Since 1980, precipitation has been measured at a weather station located on the study site. To estimate precipitation before 1980 and for months with missing data due to weather station failure, the relationship between precipitation at the site and two other longterm weather stations nearby was quantified with linear regression. Data for both these other weather stations, Portal 4 SW and San Simon, can be obtained from the National Climate Data Center (available online). ${ }^{7}$ A variety of combinations of precipitation data from the two other stations were used and the best predictor of the monthly precipitation at the study site resulted from the sum of the precipitation occurring at the two other sites in the same month. Although this relationship is not perfect $\left(r^{2}=0.683\right)$, it should provide a reasonable estimate for precipitation amounts at the study site for the time periods for which no data exist. Winter precipitation was summed from November to February and summer precipitation was summed from July to October (Fig. 1).

\section{Rodent data}

The rodents at the site have been censused monthly since 1977. Because we were interested in how seasonal rainfall was affecting rodent populations, we pooled the monthly rodent data to reflect the two rainy seasons in the Chihuahuan Desert: winter (October-March) and summer (April-September). Data from 1977 to 2000 for the 10 control plots were pooled to provide a site-wide estimate of population density.

Over 20 different species of rodents have been captured at the site. We focused our analyses on the two most consistently abundant and dominant species in the community: Dipodomys merriami (Merriam's kangaroo rat) and Dipodomys ordii (Ord's kangaroo rat). A third member of this genus has been caught at the site: Dipodomys spectabilis (banner-tailed kangaroo rat) is larger and behaviorally dominant over the smaller kangaroo rat species (Frye 1983, Brown and Munger 1985). We did not model its population dynamics, however, because it experienced a population crash in the early 1980s and disappeared from the site in the latter half of the study, making it unfeasible to apply the population models. However, population data for this species were incorporated into some of the analyses to account for a known interspecific interaction.

\section{Diagnosis and statistical models of population dynamics}

Population dynamics of desert rodents are the result of the combined effects of feedback structure (ecological interactions within and between populations), limiting factors (food limitation $=$ plants or predator limitation $=$ competition for enemy-free space), climatic influences (rainfall), and stochastic forces. To understand how these factors may determine desert rodent population fluctuations, we modeled both system-intrinsic processes (both within the population and between various trophic levels) and exogenous influences as a general model based in the $R$-function (Berryman 1999). The $R$ function represents the realized per capita population growth rates that represent the processes of individual

\footnotetext{
${ }^{7}\langle$ http://www.ncdc.noaa.gov/oa/ncdc.html $\rangle$
} 

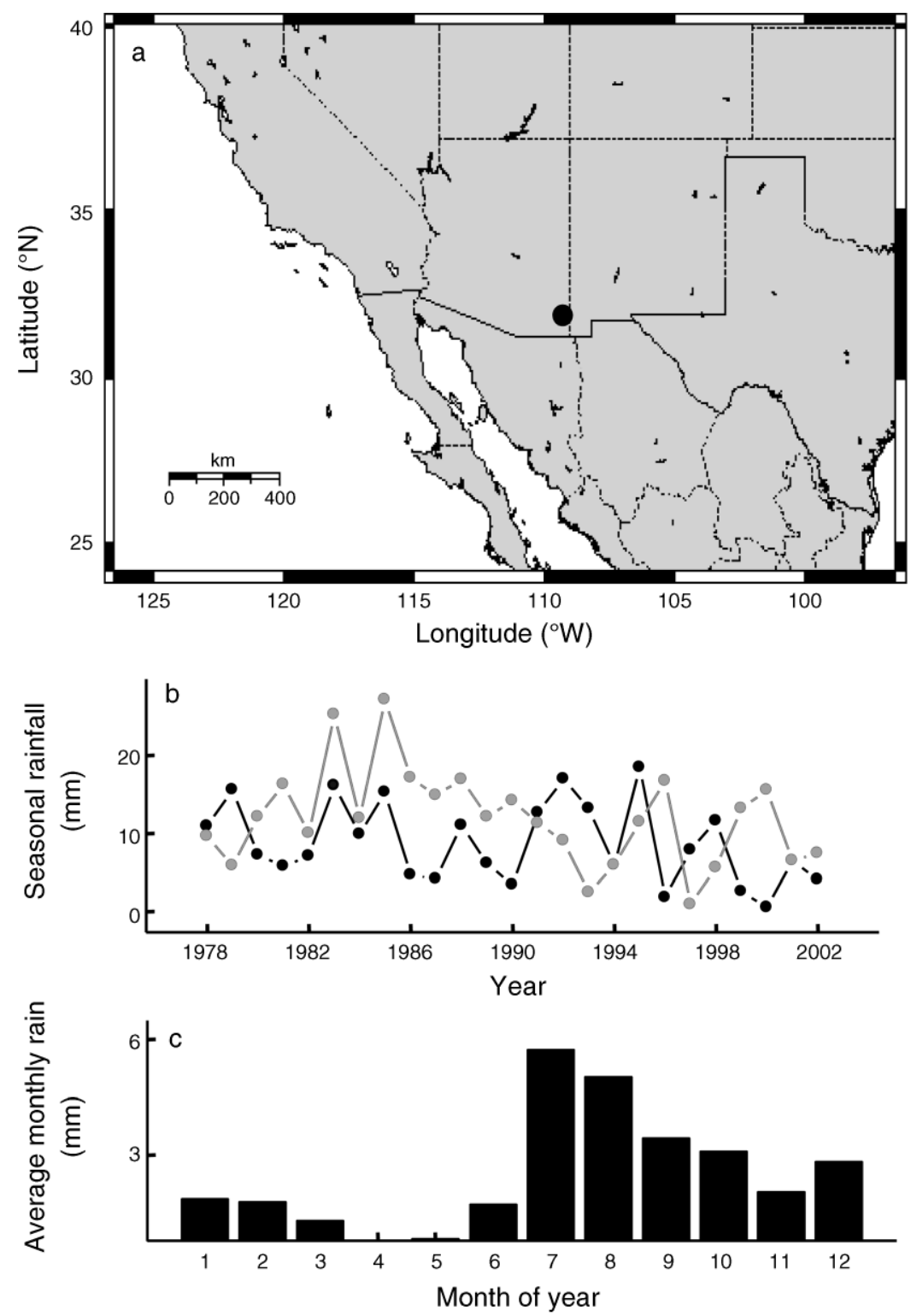

FIg. 1. (a) Map of the Southwestern USA. The black circle is the Portal study site situated in the southeastern corner of Arizona $\left(31^{\circ} 56^{\prime} 15^{\prime \prime} \mathrm{N} ; 109^{\circ} 04^{\prime} 48^{\prime \prime} \mathrm{W}\right)$; The Portal Project was initiated by James H. Brown and associates in the summer of 1977. (b) Accumulated summer rainfall (gray line and gray circles) and winter rainfall (black line and black circles) obtained from the meteorological station at Portal, 1977-2002. (c) Seasonal pattern of precipitation at the Portal site. Month 1 is January.

survival and reproduction (Berryman 1999). Defining $R_{t}$ $=\log \left(N_{t}\right)-\log \left(N_{t-1}\right)$, we can express the $R$-function as follows (sensu Berryman 1999):

$$
R_{t}=\ln \left(\frac{N_{t}}{N_{t-1}}\right)=f\left(N_{t-1}, N_{t-2}, \cdots, N_{t-p}, C_{t-1}, \varepsilon_{t}\right) .
$$

Here $N_{t-p}$ is the population size at different time lags; $C_{t-1}$ is climate effects; and $\varepsilon_{t}$ is a random normally distributed variable. This model represents the basic feedback structure and integrates the stochastic and climatic forces that drive population dynamics in nature. Our first step was to estimate the order of the dynamical processes (Royama 1977), that is how many time lags, $N_{t-i}$, should be included in the model for representing the feedback structure. To estimate the order of the process, we used the partial rate correlation, $\operatorname{PRCF}(i)$, between $R$ and $\ln N_{t-i}=X_{t-i}$ after the effects of shorter lags have been removed. We write Eq. 1 in logarithmic form to calculate the partial correlations:

$$
R_{t}=\ln \left(\frac{N_{t}}{N_{t-1}}\right)=A+B_{1} \times X_{t-1}+B_{2} \times X_{t-2}+\varepsilon_{t}
$$

Where $R$, the realized per capita rate of change, is calculated from the data, we used the Population 
Analysis System, Single-Species Time Series Analysis (PAS Version 4.0) to calculate $\mathrm{PRCF}_{t-d}$ (Ecological Systems Analysis 1987-1994). For statistical convenience, we assumed a log-linear relationship between $R$ and lagged population density (Royama 1977).

\section{Theoretical models of population dynamics}

Population dynamics of kangaroo rats are the result of intrapopulation processes that cause a first-order feedback structure in rodent fluctuations. To understand how these processes determine rodent dynamics, we used a simple model of intraspecific competition, the exponential form of the discrete logistic model (Ricker 1954, Royama 1992), and we used its generalized version (Royama 1992):

$$
N_{t}=N_{t-1} r_{\mathrm{m}} \exp \left(-c N_{t-1}^{a}\right)
$$

where $N_{t}$ represents the rodent abundance at time $t, r_{\mathrm{m}}$ is a positive constant representing the maximum finite reproductive rate, $c$ is a constant representing competition and resource depletion, and $a$ indicates the effect of interference on each individual as density increases (Royama 1992); $a>1$ indicates that interference intensifies with density and $a<1$ indicates habituation to interference. By defining Eq. 3 in terms of the $R$ function, by defining $R_{t}=\log _{e}\left(N_{t} / N_{t-1}\right)$, log-transforming Eq. 3, and defining the population density in logarithm $X_{t}=\log _{e}\left(N_{t}\right)$, we obtain

$$
R_{t}=R_{\mathrm{m}}-\exp \left(a X_{t-1}+C\right)
$$

where $R_{t}$ is the realized per capita growth rate $R_{t}=$ $\log \left(N_{t} / N_{t-1}\right), R_{\mathrm{m}}=\log \left(r_{\mathrm{m}}\right), a$ is the same parameter as in Eq. 3, $C=\log (c)$, and $X=\log (N)$. This model represents the basic feedback structure determined by intrapopulation processes.

Because in this model the three parameters $R_{\mathrm{m}}, a$, and $C$ have an explicit biological interpretation, we can include climatic perturbations in each parameter using the framework of Royama (1992). In this manner, we may build mechanistic hypotheses about the effects of climate in these two rodent populations.

For example, simple additive rainfall perturbation effects can be represented as "vertical" effects that shift the relative position of the $R$-function by changing $R_{\mathrm{m}}$ on the $y$-axis (Royama 1992). This can be expressed as

$$
R_{\mathrm{m}}^{\prime}=R_{\mathrm{m}}+g\left(\operatorname{Rain}_{t-d}\right)
$$

where $g$ is a simple linear function $(+$ or - ) of the summer or winter rainfall levels with different lags. Another kind of climatic perturbation is when the equilibrium point of the population is influenced by the climate. This is the case when climate influences a limiting factor or resource (food, shelter). The correct model structure in this scenario is that the carrying capacity (equilibrium point) is affected by the rainfall. In this case the climatic factor shifts the $R$-function curve along the $x$-axis without changing the slope at the equilibrium, that represents a "lateral" perturbation in the Royama (1992) framework:

$$
C^{\prime}=C+g\left(\text { Rain }_{t-d}\right)
$$

Finally, a climatic factor may change the intrapopulation processes by changing the intensity of competition between individuals because of the effect on a resource that is depleted during a season or year. In such a case it is expected that climate influences parameter $a$ in Eq. 4 . This kind of climatic effect is called "nonlinear" perturbation because changes in climate can change the relative shape of the $R$-function by changing the slope of the function at equilibrium $\left(R_{t}=0\right)$ :

$$
a^{\prime}=a+g\left(\text { Rain }_{t-d}\right) .
$$

In addition, we can include also in the logistic Eq. 3 a term representing interspecific competition. In this study system, we have reason to expect negative effects of the largest kangaroo rat, Dipodomys spectabilis, on the two smaller kangaroo rats, D. merriami and D. ordii. A logistic model including intra- and interspecific competition can be represented as

$$
N_{t}=N_{t-1} r_{\mathrm{m}} \exp \left(-c N_{t-1}^{a}-c_{1} N 1_{t-1}^{a 1}\right) .
$$

As in Eq. 3, $N_{t}$ represents the rodent abundance at time $t, r_{\mathrm{m}}$ is a positive constant representing the maximum finite reproductive rate, $c$ is a constant representing competition and resource depletion, and $a$ indicates the effect of interference on each individual as density increase (Royama 1992). In addition, $N 1_{t}$ is the density of the dominant competitor (D. spectabilis) with $c_{1}$ representing a constant interspecific effect on the resource depletion and $a_{1}$ indicating the effect of interference on each individual as density of $D$. spectabilis increase. We defined Eq. 8 in terms of the $R$-function by defining $R_{t}=\log _{e}\left(N_{t} / N_{t-1}\right)$, log-transforming Eq. 8, and defining the population density in logarithm $X_{t}=\log _{e}\left(N_{t}\right)$ and $X 1_{t}=\log _{e}\left(N 1_{t}\right)$, resulting in the following equation:

$$
R_{t}=R_{\mathrm{m}}-\exp \left(a X_{t-1}+a 1 X 1_{t-1}+C 1\right)
$$

where $R_{t}$ is the realized per capita growth rate $R_{t}=$ $\log \left(N_{t} / N_{t-1}\right), \quad R_{\mathrm{m}}=\log \left(r_{\mathrm{m}}\right), \quad a$ and $a 1$ are the same parameters as in Eq. 8, and $C 1=\log (c+c 1)$. This model represents the basic feedback structure determined by intra- and interpopulation processes.

We fitted Eqs. 4 and 9 using the $n l s$ (nonlinear least squares) library in the program R ( R Development Core Team 2007) by means of nonlinear regression analyses (Bates and Watts 1988). In addition, we included the climatic variables in the parameters $R_{\mathrm{m}}, C$, and $a$ as linear functions (Eqs. 5-7). All of the models were fitted by minimizing the $\mathrm{AIC}_{\mathrm{c}}=-2 \times \log ($ likelihood $)+2 p+2 p(p+$ 1)/(n-p-1), where $p$ is the number of model parameters and $n$ is the sample size. Models with the lowest $\mathrm{AIC}_{\mathrm{c}}$ values were selected. We used the data during the period 1978-1992 for fitting the models and we used the section 


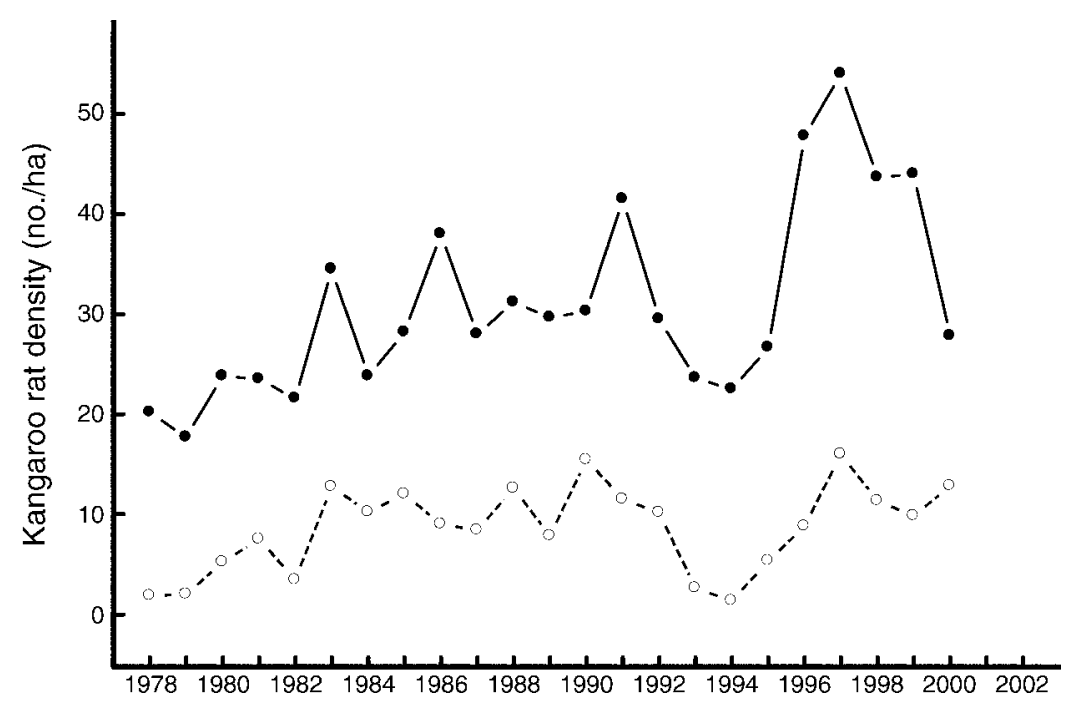

FIG. 2. Observed numerical fluctuations of Merriam's kangaroo rats (Dipodomys merriami; solid line and solid circles) and Ord's kangaroo rats (Dipodomys ordii; dashed line and open circles) from 1978 to 2000.

1993-2000 for testing the model predictions. Observed and predicted dynamics was compared using a bias parameter, calculated as $\Sigma\left(O_{i}-P_{i}\right) / 9$ where $O_{i}$ is observed data and $P_{i}$ is predicted data. Because the models of $D$. ordii showed no convergence, we used biological criteria for fixing the $R_{\mathrm{m}}$ parameter (maximum per capita growth rates) (see Royama 1992). The maximum value observed of the per capita growth rate was 1.39; which is consistent with the life history of this species, two litters per year producing, on average, 3.3 individuals/year (Garrison and Best 1990) and a mortality rate of $0.35 /$ year (Brown and Zeng 1989), then we can estimate an average $R=\log _{e}(1+B-D)$ (Berryman 1999), where $B$ is per capita birth rate $(3.3 /$ year) and $D$ is per capita death rate $(0.35 /$ year $)$, including these values the average $R$ is 1.37 . Therefore we fixed this value in 1.50 for estimating the other model parameters.

\section{RESUlts}

The numerical fluctuations of the two dominant kangaroo rats were quite similar. Merriam's kangaroo rat (Dipodomys merriami) was characterized by irregular oscillations and a sudden decrease during the period 1992-1995 and an increasing trend during the last years of the time series (Fig. 2). Similar dynamics were observed in the other important rodent, Ord's kangaroo rat (Dipodomys ordii), suggesting that common factors are operating in both species (Fig. 2). First-order negative feedback, PRCF(1), was the most important component of per capita growth rates in the two species analyzed (Table 1). These results suggest that first-order negative feedback is the most important component of these two small-rodent feedback structures.

According to our analyses, the logistic model without exogenous effects accounts for $40 \%$ and $35 \%$ of the observed variation in $R$ values of $D$. merriami and
$D$. ordii, respectively (Table 2 ). Our second step was to look for the rainfall effect to explain the residual variation of the logistic model. In both species the direct effects of summer rainfall showed a positive and significant correlation with the model residuals ( $D$. merriami, summer rainfall, $r=0.55, P=0.034 ; D$. ordii, summer rainfall, $r=0.72, P=0.003$ ), whereas the residual variation showed no significant effects of winter rainfall ( $D$. merriami, winter rainfall, $r=-0.25, P=0.37$; $D$. ordii, winter rainfall, $r=-0.33, P=0.23)$. For both species (Table 2), models including summer rainfall showed lower $\mathrm{AIC}_{\mathrm{c}}$ values than models including winter rainfall. The Akaike weights indicate a very strong support for the role of summer rainfall as the main exogenous perturbation effect; the evidence ratio between models is strong for summer rainfall models (for example, $w_{2} / w_{3}=11.11$ ).

The addition of the summer rainfall as an exogenous perturbation effect in $D$. merriami increases the explained variance from $40 \%$ to $60 \%$ (models 2, 4, and 6 in Table 2) and the $\mathrm{AIC}_{\mathrm{c}}$ criteria and Akaike weights were very similar between the three models (Table 2).

TABLE 1. Diagnostic analysis of the feedback structure of kangaroo rats, $\mathrm{PRCF}_{t-i}$, the partial rate correlation between $R$ and $\ln N_{t-i}$.

\begin{tabular}{lccc}
\hline \hline \multicolumn{1}{c}{ Species } & $\mathrm{PRCF}_{t-1}$ & $\mathrm{PRCF}_{t-2}$ & $\mathrm{PRCF}_{t-3}$ \\
\hline Dipodomys merriami & $\mathbf{- 0 . 5 7}$ & -0.19 & -0.25 \\
Dipodomys ordii & $\mathbf{- 0 . 5 4}$ & -0.20 & -0.13 \\
\hline
\end{tabular}

Notes: $\mathrm{PRCF}_{t-i}$ analysis provides an estimate of the order of the autoregressive process (Berryman 1999, Berryman and Turchin 2001). We interpret this to be a measure of the importance, or the relative contributions, of feedback at lag $i(i$ $=1,2$, and 3 ) to the determination of $R$, the per capita population growth rate of a population with $N$ individuals. Values are correlation coefficients; boldface indicates significance at $P<0.05$. 
TABLE 2. Optimal population dynamic models for kangaroo rats using the exponential $\left(R_{t}=R_{\mathrm{m}}-\exp \left[a X_{t-1}+C\right]\right)$ form of logistic growth (Royama 1992); parameter values are given in the equations.

\begin{tabular}{|c|c|c|c|c|c|c|c|}
\hline Models for kangaroo rats & $\begin{array}{l}\text { Log- } \\
\text { likelihood }\end{array}$ & $\mathrm{AIC}_{\mathrm{c}}$ & $p$ & $\Delta \mathrm{AIC}_{\mathrm{c}}$ & $w_{i}$ & $R^{2}$ & Bias \\
\hline \multicolumn{8}{|l|}{ Dipodomys merriami } \\
\hline 1) $R_{t}=0.25-\exp \left[2.95 X_{t-1}-11.44\right]$ & 3.33 & 5.33 & 4 & 8.16 & 0.0058 & 0.40 & \\
\hline \multicolumn{8}{|l|}{ Vertical effects } \\
\hline $\begin{array}{l}\text { 2) } R_{t}=-0.036-\exp \left[2.93 X_{t-1}-11.51\right]+0.018 \mathrm{Sr}_{t} \\
\text { 3) } R_{t}=0.39-\exp \left[2.57 X_{t-1}-9.96\right]-0.011 \mathrm{Wr}_{t}\end{array}$ & $\begin{array}{l}6.23 \\
3.82\end{array}$ & $\begin{array}{l}4.21 \\
9.03\end{array}$ & $\begin{array}{l}5 \\
5\end{array}$ & $\begin{array}{r}7.03 \\
11.86\end{array}$ & $\begin{array}{l}0.010 \\
0.0009\end{array}$ & $\begin{array}{l}0.60 \\
0.45\end{array}$ & $9.57(9.96)$ \\
\hline \multicolumn{8}{|l|}{ Lateral effects } \\
\hline $\begin{array}{l}\text { 4) } R_{t}=1.13-\exp \left[0.50 X_{t-1}-1.29-0.018 \mathrm{Sr}_{t}\right] \\
\text { 5) } R_{t}=0.28-\exp \left[2.52 X_{t-1}-10.18+0.039 \mathrm{Wr}_{t}\right]\end{array}$ & $\begin{array}{l}5.79 \\
3.93\end{array}$ & $\begin{array}{l}5.09 \\
8.81\end{array}$ & $\begin{array}{l}5 \\
5\end{array}$ & $\begin{array}{r}7.91 \\
11.63\end{array}$ & $\begin{array}{l}0.0066 \\
0.0010\end{array}$ & $\begin{array}{l}0.58 \\
0.46\end{array}$ & $11.11(7.65)$ \\
\hline \multicolumn{8}{|l|}{ Nonlinear effects } \\
\hline $\begin{array}{l}\text { 6) } R_{t}=1.59-\exp \left[\left(0.40-0.0038 \mathrm{Sr}_{t}\right) X_{t-1}-0.69\right] \\
\text { 7) } R_{t}=0.29-\exp \left[\left(2.32+0.0108 \mathrm{Wr}_{t}\right) X_{t-1}-9.47\right]\end{array}$ & $\begin{array}{l}5.66 \\
3.92\end{array}$ & $\begin{array}{l}5.34 \\
8.83\end{array}$ & $\begin{array}{l}5 \\
5\end{array}$ & $\begin{array}{r}8.16 \\
11.65\end{array}$ & $\begin{array}{l}0.0058 \\
0.0010\end{array}$ & $\begin{array}{l}0.57 \\
0.46\end{array}$ & $11.4(7.92)$ \\
\hline $\begin{array}{l}\text { Interspecific competition } \\
\quad \text { 8) } R_{t}=0.255-\exp \left[3.37 X_{t-1}-13.29+0.25 X^{D s}{ }_{t-1}\right]\end{array}$ & 4.19 & 8.30 & 5 & 11.12 & 0.0013 & 0.48 & $1.25(5.27)$ \\
\hline $\begin{array}{l}\text { Summer rainfall and interspecific competition } \\
\text { 9) } R_{t}=0.65-\exp \left[0.81 X_{t-1}-3.01+0.16 X_{t-1}^{\mathrm{Ds}}\right]+0.027 \mathrm{Sr}_{t} \\
\text { 10) } R_{t}=0.53-\exp \left[1.58 X_{t-1}-5.61-0.07 \mathrm{Sr}_{t}+0.29 X_{t-1}^{\mathrm{Ds}}\right] \\
\text { 11) } R_{t}=0.67-\exp \left[\left(1.44-0.016 \mathrm{Sr}_{t}\right) X_{t-1}-5.00+0.24 X_{t-1}^{\mathrm{Ds}}\right]\end{array}$ & $\begin{array}{l}11.66 \\
12.52 \\
12.63\end{array}$ & $\begin{array}{l}-2.82 \\
-2.52 \\
-2.75\end{array}$ & $\begin{array}{l}6 \\
6 \\
6\end{array}$ & $\begin{array}{l}0.00 \\
0.30 \\
0.07\end{array}$ & $\begin{array}{l}0.34 \\
0.29 \\
0.33\end{array}$ & $\begin{array}{l}0.81 \\
0.83 \\
0.83\end{array}$ & $\begin{array}{l}0.36(0.18) \\
3.69(3.17) \\
3.07(2.65)\end{array}$ \\
\hline $\begin{array}{l}\text { Dipodomys ordii } \\
\text { 12) } R_{t}=1.16-\exp \left[0.67 X_{t-1}-1.30\right]\end{array}$ & \multicolumn{6}{|c|}{ Dipodomys ordii } & \\
\hline \multicolumn{8}{|l|}{ Vertical effects } \\
\hline $\begin{array}{l}\text { 13) } R_{t}=1.50 \exp \left[0.27 X_{t-1}+0.299\right]+0.063 \mathrm{Sr}_{t} \\
\text { 14) } R_{t}=1.50-\exp \left[0.65 X_{t-1}-1.264\right]-0.036 \mathrm{Wr}_{t}\end{array}$ & $\begin{array}{r}-5.60 \\
-10.72\end{array}$ & $\begin{array}{l}23.20 \\
33.44\end{array}$ & $\begin{array}{l}4 \\
4\end{array}$ & $\begin{array}{r}0.21 \\
10.45\end{array}$ & $\begin{array}{l}0.324 \\
0.002\end{array}$ & $\begin{array}{l}0.71 \\
0.42\end{array}$ & $3.49(2.71)$ \\
\hline \multicolumn{8}{|l|}{ Lateral effects } \\
\hline $\begin{array}{l}\text { 15) } R_{t}=1.50-\exp \left[0.38 X_{t-1}+0.246-0.049 \mathrm{Sr}_{t}\right] \\
\text { 16) } R_{t}=1.50-\exp \left[0.46 X_{t-1}-0.822+0.026 \mathrm{Wr}_{t}\right]\end{array}$ & $\begin{array}{r}-5.50 \\
-10.64\end{array}$ & $\begin{array}{l}22.99 \\
33.29\end{array}$ & $\begin{array}{l}4 \\
4\end{array}$ & $\begin{array}{r}0.00 \\
10.30\end{array}$ & $\begin{array}{l}0.360 \\
0.002\end{array}$ & $\begin{array}{l}0.71 \\
0.43\end{array}$ & $4.00(2.92)$ \\
\hline \multicolumn{8}{|l|}{ Nonlinear effects } \\
\hline $\begin{array}{l}\text { 17) } R_{t}=1.50-\exp \left[\left(0.63-0.021 \mathrm{Sr}_{t}\right) X_{t-1}-0.35\right] \\
\text { 18) } R_{t}=1.50-\exp \left[\left(0.35+0.010 \mathrm{Wr}_{t}\right) X_{t-1}-0.55\right]\end{array}$ & $\begin{array}{r}-7.18 \\
-10.74\end{array}$ & $\begin{array}{l}26.35 \\
33.48\end{array}$ & $\begin{array}{l}4 \\
4\end{array}$ & $\begin{array}{r}3.36 \\
10.48\end{array}$ & $\begin{array}{l}0.067 \\
0.002\end{array}$ & $\begin{array}{l}0.64 \\
0.42\end{array}$ & $3.26(2.79)$ \\
\hline \multicolumn{8}{|l|}{ Interspecific competition } \\
\hline $\begin{array}{l}\text { Summer rainfall and interspecific competition } \\
\left.\text { 20) } R_{t}=1.50-\exp \left[0.30 X_{t-1}+0.175+0.065 X_{t-1}^{\mathrm{Ds}}\right]+0.074 \mathrm{Sr}_{t}\right] \\
\text { 21) } R_{t}=1.50-\exp \left[0.46 X_{t-1}+0.012-0.062 \mathrm{Sr}_{t}+0.12 X_{t-1}^{\mathrm{Ds}}\right] \\
\text { 22) } R_{t}=1.50-\exp \left[\left(0.76-0.025 \mathrm{Sr}_{t}\right) X_{t-1}-0.71+0.11 X_{t-1}^{\mathrm{Ds}}\right]\end{array}$ & $\begin{array}{l}-4.78 \\
-4.03 \\
-6.18\end{array}$ & $\begin{array}{l}26.22 \\
24.72 \\
29.02\end{array}$ & $\begin{array}{l}5 \\
5 \\
5\end{array}$ & $\begin{array}{l}3.23 \\
1.73 \\
6.03\end{array}$ & $\begin{array}{l}0.072 \\
0.152 \\
0.018\end{array}$ & $\begin{array}{l}0.74 \\
0.76 \\
0.69\end{array}$ & $\begin{array}{l}1.51(1.26) \\
1.88(1.36) \\
1.27(1.40)\end{array}$ \\
\hline
\end{tabular}

Notes: The best population dynamic models for both kangaroo rat species were chosen by using the Akaike Information Criteria for small sample size, $\mathrm{AIC}_{\mathrm{c}}$. Model parameters were estimated by nonlinear regression analysis in R-program using the nls (nonlinear least squares) library (R Development Core Team 2007). The model notations are: $R_{\mathrm{m}}$, maximum per capita growth rate; $a$, effect of interference on each individual as density increases; $C$, a constant representing competition and resource depletion; $X_{t-1}$, $\log$ population abundance; $X_{t-1}^{\mathrm{Ds}}$, density of Dipodomys spectabilis; $\mathrm{Sr}$, summer rainfall; $\mathrm{Wr}$, winter rainfall; $p$, number of model parameters; $\Delta \mathrm{AIC}_{\mathrm{c}}=$ model $\Delta \mathrm{AIC}_{\mathrm{c}}-$ lowest $\Delta \mathrm{AIC}_{\mathrm{c}} ; w_{i}$, Akaike weights. We calculated a bias parameter, calculated as $\Sigma\left(O_{i}-P_{i}\right) / 9$, where $O_{i}$ is observed data and $P_{i}$ is predicted data. In the Bias column, values in parentheses are bias parameters estimated using one-step-ahead predictions.

Model predictions for the period 1993-2000 showed that the three models were quite good in predicting the crash during 1993-1995, but they failed to predict the posterior population recovery (Fig. 3a). The model including only the interspecific effects of $D$. spectabilis showed a bias parameter near to 0 but it was not able to predict the observed population dynamics (Fig. 3b), compared with a model including only summer rainfall this model was 7.7 times less likely according to the evidence ratio $\left(w_{2} / w_{8}\right)$. However, the models including the interspecific effects of $D$. spectabilis and summer rainfall (models 9, 10, and 11 in Table 2) showed the lowest $\mathrm{AIC}_{\mathrm{c}}$ values and the evidence ratio with the models including only summer rainfall $\left(w_{9} / w_{2}=34\right)$ indicate a very strong empirical support for models 9 , 10, and 11 (Table 2). These models predicted very well the decrease observed during the period 1992-1995 and the posterior recovery according to the bias parameter. This is particularly true for the model with vertical summer rainfall effects (Fig. 3c, Table 2).

The addition of summer rainfall as an exogenous perturbation effect in $D$. ordii increases the explained variance from $35 \%$ to $71 \%$ (models 13,15 , and 17 in Table 2), and the $\mathrm{AIC}_{\mathrm{c}}$ criteria were very similar between models 13 and 15 (Table 2). The evidence ratio showed that models including summer rainfall have 180 times 

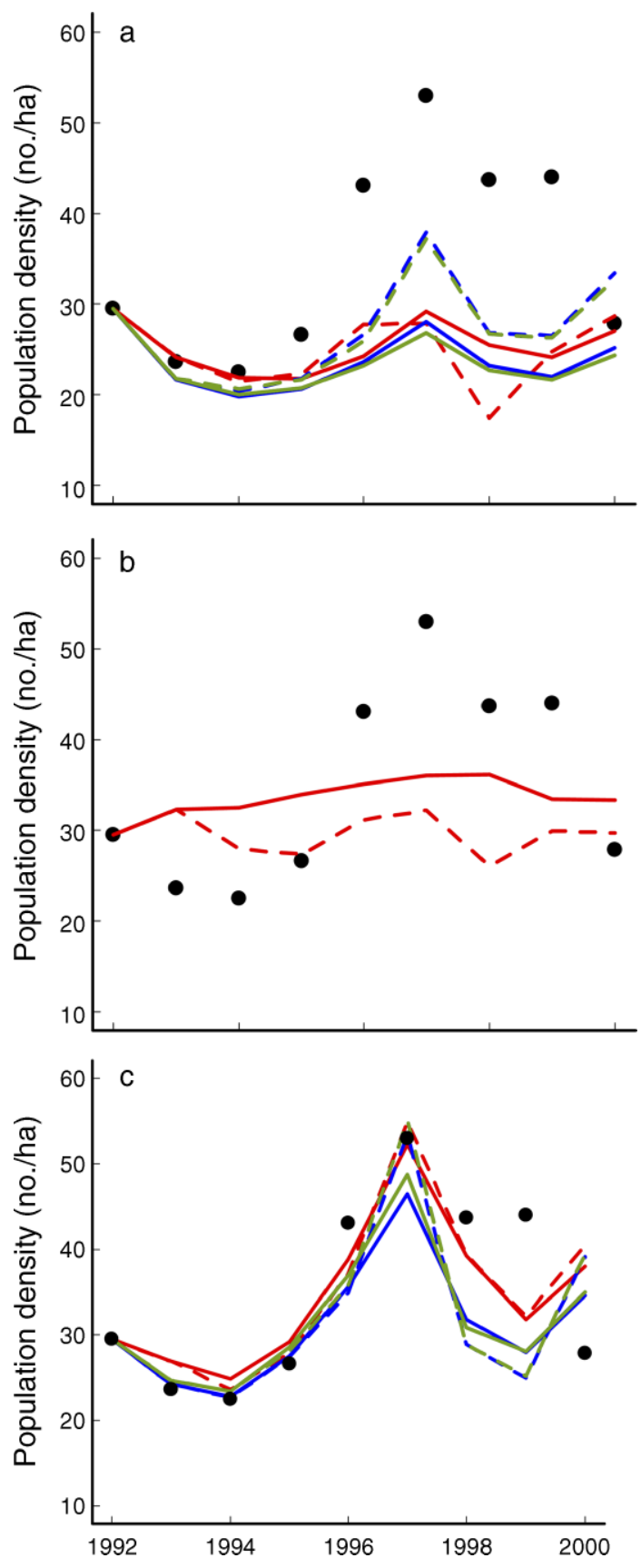

FIG. 3. Comparison of observed Merriam's kangaroo rat densities (solid circles) for the period 1993-2000 with predictions from models fitted to the data until the year 1992: red lines, vertical perturbation effects; blue lines, lateral perturbation effects; green lines, nonlinear perturbation effects. Solid lines are total trajectories predictions, and dashed lines are onestep-ahead predictions). (a) Models 2, 4, and 6 (summer rainfall effects); (b) model 8 (D. spectabilis effects); and (c) models 9, 10, and 11 (summer rainfall and D. spectabilis effects). All models are from Table 2 . more empirical support than winter rainfall models $\left(w_{15} / w_{16}=180\right)$. Model predictions for the period 19932000 showed that the three models were quite good in predicting the crash during 1993-1995, but not the posterior recovery (Fig. 4a). Similarly to D. merriami, the models including interspecific effects of $D$. spectabilis were not able to predict the observed population dynamics (Fig. 4b). The models including the effect of summer rainfall and D. spectabilis showed higher $\mathrm{AIC}_{\mathrm{c}}$ than models with only summer rainfall effects (Table 2); the evidence ratio gives support to models with only summer rainfall $\left(w_{15} / w_{21}=2.37\right)$. However, the inclusion of D. spectabilis and summer rainfall (models 20, 21, and 22 in Table 2) improve model predictions by reducing the bias parameter (Fig. 4c, Table 2), although it is important to note that the best models predicted lower densities than the observed data for the years 1998-1999 in both species.

\section{DisCusSION}

Our analyses of these two kangaroo rat species in the Chihuahuan Desert showed that the combined effects of intra- and interspecific processes with summer rainfall are the key factors for determining population fluctuations of these small rodents. Our results are consistent with previous studies (Munger and Brown 1981, Heske et al. 1994, Valone and Brown 1995) showing the importance of competition for explaining the dynamics in this rodent community. However, this study also brings a new interpretation concerning the complex role of rainfall as a limiting factor in this desert ecosystem, and the subsequent rodent responses. We will discuss the use of simple theory-based models for interpreting climatic effects and how we can use these models for predicting the putative ecological mechanisms.

One interesting result is that our simple models were able to decipher the key role that summer rainfall plays for kangaroo rats in this desert ecosystem. Exactly why summer rainfall appears to influence population dynamics more than does winter precipitation is unclear. Because previous studies at this site have shown that kangaroo rats significantly impact the species composition of the winter annual community, but not the summer annual community (Guo and Brown 1996), it has been assumed that the winter annual community might be more important for kangaroo rat population dynamics. However, kangaroo rats have also been shown to significantly decrease the cover of summer grasses (Brown and Heske 1990). Although this decrease in grasses is thought to be mainly due to soil disturbance by kangaroo rats, it could also be due to kangaroo rat foraging (Heske et al. 1993), indicating that summer seeds could be important for these species. It is also possible that summer precipitation is important not because of seed resources but because it increases other resources necessary for reproduction. Some studies suggest that summer precipitation may be important not because of seed production but because $D$. merriami 
needs green vegetation in order to reproduce (Bradley and Maurer 1971, Reichman and Van de Graaf 1975, Soholt 1977); specifically, females require the water contained in green vegetation for lactation (Soholt 1977). Regardless of the exact process that makes summer precipitation important to Dipodomys, summer precipitation accounts for over $60 \%$ of the precipitation that occurs at the site (Brown and Ernest 2002) and it seems plausible that the season with the highest average precipitation would be more important in determining rodent dynamics. However, it is important to note that our model underestimated the observed densities for 1998 and 1999. Although we do not know why this occurred, it is interesting that the years previous to those (1997-1998) were characterized by dry summers and wet winters. It is possible that wet winters could compensate for drier summers and that an interaction between winter and summer rainfall may be important for completely understanding the dynamics of these two species.

Although there has been speculation that summer rainfall might be important for understanding population dynamics (Ernest et al. 2000, Brown and Ernest 2002), previous studies at this site could not detect a significant rainfall effect on rodent dynamics. Our modeling approach clearly showed the importance of summer rainfall for determining the per capita growth rates of kangaroo rats. We think that there are two explanations as to why previous studies did not discover a statistical relationship between rainfall and rodent responses. First, as Ernest and colleagues speculated (Ernest et al. 2000, Brown and Ernest 2002), the relationship between precipitation and rodents is complex and nonlinear, and a strong correlation between population density and an exogenous factor can only be detected if the underlying population dynamics process is linear, first order, and perfectly regulated around the equilibrium point (Royama 1992). In other words, a low correlation coefficient between population density and the climatic factor is not strong evidence against the importance of this factor, because the existence of nonlinearity in the population dynamics will mask the effect of climate on population fluctuations. In fact, the estimated parameter $a$ in both rodent species showed values quite different from 1 , indicating a strong nonlinearity in the population dynamics. For $D$. merriami models, the value of parameter $a$ was always $>1$, but for $D$. ordii models, $a<1$, indicating more intense intraspecific competition for the former species. This parameter represents how fast the maximum per capita growth rate $\left(R_{\mathrm{m}}\right)$ is reduced when new individuals recruit into the population; when $a>1$, the reduction is faster than when $a<1$ (Royama 1992). Another related problem is that when rainfall is influencing a limiting factor, for example, plants or seeds in arid ecosystems, it is very likely that, in those cases, rainfall represents a lateral or nonlinear perturbation effect for rodent dynamics (see Royama 1992). The problem with this kind of exogenous effect is that it affects the availability
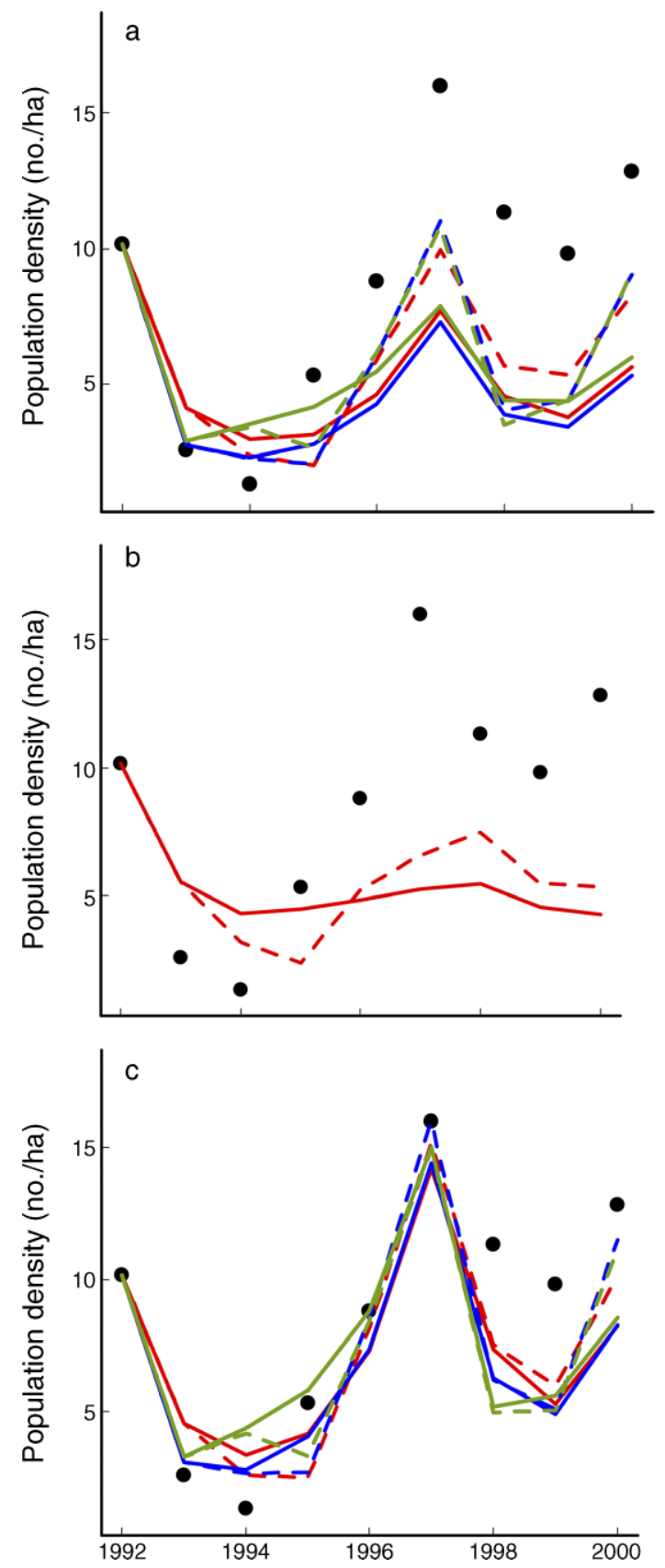

Fig. 4. Comparison of observed Ord's kangaroo rat densities (solid circles) for the period 1993-2000 with predictions from models fitted to the data until the year 1992: red lines, vertical perturbation effects; blue lines, lateral perturbation effects; green lines, nonlinear perturbation effects. Solid lines are total trajectories predictions, and dotted lines are onestep-ahead predictions). (a) Models 13, 15, and 17 (summer rainfall effects); (b) model 19 (D. spectabilis effects); and (c) models 20, 21, and 22 (summer rainfall and D. spectabilis effects). All models are from Table 2.

of some limiting factor or resource (e.g., food); hence, the per capita resource share of individuals is also influenced (Royama 1992). In consequence, the effect of the climatic variable cannot be evaluated independently of the 
population density level, because the exogenous effect (e.g., rainfall) acts jointly with population density (Royama 1992, Berryman and Lima 2006, Lima and Berryman 2006, Lima et al. 2006), resulting in potentially nonlinear responses of populations to changes in climate.

Our logistic models appear to capture the essential features of the observed fluctuations and suggest a mechanistic explanation for these fluctuations. In particular, we were able to predict the sudden population decrease of both kangaroo rat species that occurred during the period 1993-1995, using models fitted to independent data; we attributed this crash to three consecutive years of low summer rainfall levels (1992, 1993, and 1994). There were not large differences in model predictions using summer rainfall as a vertical, lateral, or nonlinear perturbation. However, because an increase in summer rainfall should reduce the intensity of competition between individuals, we expect that models including summer rainfall as a proxy of a limiting factor or model will perform better than models including summer rainfall as a vertical perturbation effect. In fact, a recent study in a semiarid ecosystem in western South America determined that population fluctuations of the small rodent Phyllotis darwini were better predicted by a logistic model in which the rainfall acts on $K$, causing a lateral perturbation to the $R$ function (Lima et al. 2006). Our results are consistent with this finding.

Although climate, specifically summer rainfall, proved to be an important driver of the populations of $D$. merriami and D. ordii, it was not sufficient to explain all of the important dynamics. Interestingly, the logistic models including the interspecific effect of the largest kangaroo rat, Dipodomys spectabilis, on the per capita rates of the other two species were able to improve the model predictions. This is consistent with previous experimental work on these species (Frye 1983, Brown and Munger 1985). For example, the high densities reached by $D$. merriami during 1997 after the population crash (1992-1996) appear to be the product of a high summer rainfall year and the disappearance of $D$. spectabilis from the Portal site. This suggests that, to understand the response of populations to climate, we must also know the dynamics of important competitors. If the populations of dominant competitors are high, then response to climate may be dampened or modified by these biotic interactions. The importance of biotic interactions for modifying response to climate is not limited to competition, but also has been documented for predation (Lima et al. 2002a, b). It is unfortunate that the lack of enough D. spectabilis individuals in the second half of the study precluded analysis of the dynamics of that species, because previous work has implicated climate and habitat change in the crash of that species (Valone et al. 1995, Brown et al. 1997). Taken together, these results suggest that climate can change the competitive structure of a community, thus altering the response of a species to the dynamics of climate.
One important point is that this simple model is based on strong logic and theoretical arguments (Royama 1992, Berryman 1999), but it also shows important predictive power (Figs. 3 and 4). This approach supports the view that analysis of population data should be done within the framework of theoretical models (Berryman 1992, 1999, Royama 1992). Finally, logistic models expressed in terms of ecological demand/offer ratios represent a very plausible theoretical model structure for representing natural populations (Leslie 1948, Berryman 1999).

\section{CONCLUSION}

Our results show that simple models can be useful in explaining and predicting the dynamics of natural populations, particularly when they are based on a sound theoretical framework (Royama 1992, Berryman 1999). In particular, Royama's (1992) classification of exogenous perturbation effects has been extremely useful in population modeling. Using these models together with Royama's (1992) paradigm for classifying exogenous (climate) perturbations, we were able to distinguish how seasonal rainfall influences two rodent populations and to predict independent data. The remarkable simplicity and generality (Ginzburg and Colyvan 2004) of the models used here appear to be very successful in explaining rodent fluctuations at an arid ecosystem of southwestern North America, suggesting that this is a strong and useful approach for incorporating the role of exogenous factors such as climate and interspecific interactions into population models.

\section{ACKNOWLEDGMENTS}

M. Lima was funded by grant FONDAP-FONDECYT 1501-0001 to the Center for Advanced Studies in Ecology and Biodiversity, and this is a contribution of Research Program 2 to CASEB. The Portal Project is currently funded by a NSF Long-term Research in Environmental Biology (LTREB) collaborative grant to J. H. Brown and T. J. Valone (DEB0348896).

\section{Literature Cited}

Andrewartha, H. G., and L. C. Birch. 1954. The distribution and abundance of animals. University of Chicago Press, Chicago, Illinois, USA.

Bates, D. M., and D. G. Watts. 1988. Nonlinear regression analysis and its applications. John Wiley, New York, New York, USA.

Berryman, A. A. 1992. On choosing models for describing and analyzing ecological time series. Ecology 73:694-698.

Berryman, A. A. 1999. Principles of population dynamics and their applications. Stanley Thornes Publishers, Cheltenham, UK.

Berryman, A. A., and M. Lima. 2006. Deciphering the effects of climate on animal populations: diagnostic analysis provides new interpretation of Soay sheep dynamics. American Naturalist 168:784-795.

Berryman, A. A., and P. Turchin. 2001. Identifying the densitydependent structure underlying ecological time series. Oikos 92:265-270.

Bradley, W. G., and R. A. Maurer. 1971. Reproduction and food habits of Merriam's Kangaroo Rat, Dipodomys merriami. Journal of Mammalogy 52:497-507.

Brown, J. H. 1998. The desert granivory experiments at Portal. Pages 71-95 in W. L. Resetarits, Jr. and J. Bernardo, editors. 
Issues and perspectives in experimental ecology. Oxford University Press, Oxford, UK.

Brown, J. H., and S. K. M. Ernest. 2002. Rain and rodents: complex dynamics of desert consumers. BioScience 52:979987.

Brown, J. H., and E. J. Heske. 1990. Temporal changes in a Chihuahuan Desert rodent community. Oikos 59:290-302.

Brown, J. H., and J. C. Munger. 1985. Experimental manipulation of a desert rodent community. Ecology 66: $1545-1563$.

Brown, J. H., T. J. Valone, and C. G. Curtin. 1997. Reorganization of an arid ecosystem in response to recent climate change. Proceedings of the National Academy of Sciences (USA) 94:9729-9733.

Brown, J. H., and Z. Zeng. 1989. Comparative population ecology of eleven species of rodents in the Chihuahuan Desert. Ecology 70:1507-1525.

Ecological Systems Analysis. 1987-1994. Population Analysis System (PAS). Version 4.0. Ecological Systems Analysis, Pullman, Washington, USA. 〈http://classes.entom.wsu.edu/ pas/>

Elton, C. 1924. Fluctuations in the numbers of animals. British Journal of Experimental Biology 2:119-163.

Ernest, S. K. M., J. H. Brown, and R. R. Parmenter. 2000. Rodents, plants, and precipitation: spatial and temporal dynamics of consumers and resources. Oikos 88:470-482.

Frye, R. J. 1983. Experimental field evidence of interspecific competition between two species of kangaroo rat (Dipodomys). Oecologia 59:74-78.

Garrison, T. E., and T. L. Best. 1990. Dipodomys ordii. Mammalian Species 353:1-8.

Ginzburg, L. R., and M. Colyvan. 2004. Ecological orbits. How planets move and populations grow. Oxford University Press, New York, New York, USA.

Guo, Q. F., and J. H. Brown. 1996. Temporal fluctuations and experimental effects in desert plant communities. Oecologia 107:568-577.

Heske, E. J., J. H. Brown, and Q. F. Guo. 1993. Effects of kangaroo rat exclusion on vegetation structure and plantspecies diversity in the Chihuahuan Desert. Oecologia 95: $520-524$.

Heske, E. J., J. H. Brown, and S. Mistry. 1994. Long-term experimental study of a Chichuahuan Desert rodent community: 13 years of competition. Ecology 75:438-445.

Holmgren, M., M. Scheffer, E. Ezcurra, J. R. Gutierrez, and G. M. J. Mohren. 2001. El Niño effects on the dynamics of terrestrial ecosystems. Trends in Ecology and Evolution 16: 89-94.

Jaksic, F. M. 2001. Ecological effects of El Niño in terrestrial ecosystems of western South America. Ecography 24:241-250.

Jaksic, F. M., S. I. Silva, P. L. Meserve, and J. R. Gutiérrez. 1997. A long-term study of vertebrate predator responses to an El Niño (ENSO) disturbance in western South America. Oikos 78:341-354.

Leirs, H., N. C. Stenseth, J. D. Nichols, J. E. Hines, R. Verhagen, and W. Verheyen. 1997. Stochastic seasonality and nonlinear density-dependent factors regulate population size in an African rodent. Nature 389:176-180.

Leslie, P. H. 1948. Some further notes on the use of matrices in population mathematics. Biometrika 35:213-245.

Lewellen, R. H., and S. H. Vessey. 1998. The effect of density dependence and weather on population size of a polyvoltine species. Ecological Monographs 68:571-594.

Lima, M., and A. A. Berryman. 2006. Predicting nonlinear and non-additive effects of climate: the alpine ibex revisited. Climate Research 32:129-135.

Lima, M., J. E. Keymer, and F. M. Jaksic. 1999. ENSO-driven rainfall variability and delayed density dependence cause rodent outbreaks in western South America: linking demography and population dynamics. American Naturalist 153: 476-491.

Lima, M., M. A. Previtali, and P. Meserve. 2006. Climate and small rodent dynamics in semi-arid Chile: the role of lateral and vertical perturbations and intra-specific processes. Climate Research 30:125-132.

Lima, M., N. C. Stenseth, and F. M. Jaksic. 2002a. Population dynamics of a South American small rodent: seasonal structure interacting with climate, density-dependence and predator effects. Proceedings of the Royal Society B 269: $2579-2586$.

Lima, M., N. C. Stenseth, and F. M. Jaksic. 2002b. Food web structure and climate effects in the dynamics of small mammals and owls in semiarid Chile. Ecology Letters 5: 273-284.

Lima, M., N. C. Stenseth, N. G. Yoccoz, and F. M. Jaksic. 2001. Demography and population dynamics of the mouseoppossum (Thylamys elegans) in semiarid Chile: feedback structure and climate. Proceedings of the Royal Society B 268:2053-2064.

Mock, C. J. 1996. Climatic controls and spatial variation of precipitation in the western United States. Journal of Climate 9:1111-1125.

Munger, J. C., and J. H. Brown. 1981. Competition in desert rodents: an experiment with semi-permeable exclosures. Science 211:510-512.

Nicholson, A. J. 1933. The balance of animal populations. Journal of Animal Ecology 2:132-178.

R Development Core Team. 2007. R: A language and environment for statistical computing. Version 2.5.1. R Foundation for Statistical Computing, Vienna, Austria. $\langle$ http://www.cran.r-project.org/〉

Reichman, O. J., and K. M. Van de Graaf. 1975. Association between ingestion of green vegetation and desert rodent reproduction. Journal of Mammalogy 56:503-506.

Ricker, W. E. 1954. Stock and recruitment. Journal of Fisheries Research Board of Canada 11:559-623.

Royama, T. 1977. Population persistence and density dependence. Ecological Monographs 47:1-35.

Royama, T. 1992. Analytical population dynamics. Chapman and Hall, London, UK.

Sæther, B.-E., J. Tufto, S. Engen, K. Jerstad, O. W. Røstad, and J. E. Skåtan. 2000. Population dynamical consequences of climate change for a small temperate song bird. Science 287:854-856.

Soholt, L. F. 1977. Consumption of herbaceous vegetation and water during reproduction and development of Merriam's kangaroo rat, Dipodomys merriami. American Midland Naturalist 98:445-457.

Stenseth, N. C. 1999. Population cycles in voles and lemmings: density-dependence and phase dependence in a stochastic world. Oikos 87:427-461.

Stenseth, N. C., A. Mysterud, G. Ottersen, J. W. Hurrell, K. S. Chan, and M. Lima. 2002. Ecological effects of climate fluctuations. Science 297:1292-1296.

Valone, T. J., and J. H. Brown. 1995. Effects of competition, colonization, and extinction on rodent species diversity. Science 267:880-883.

Valone, T. J., J. H. Brown, and C. L. Jacobi. 1995. Catastrophic decline of a desert rodent, Dipodomys spectabilis: insights from a long-term study. Journal of Mammalogy 76:428-436.

Walther, G.-R., E. Post, P. Convey, A. Menzel, C. Parmesan, T. J. C. Beebee, J.-M. Fromentin, O. Hoegh-Guldberg, and F. Bairlein. 2002. Ecological responses to recent climate change. Nature 416:389-395. 